\title{
Effects of stocking density on growth performance, carcass grade and immunity of pigs housed in sawdust fermentative pigsties
}

\author{
K.H. Kim, E.S. Cho, K.S. Kim, J.E. Kim, K.H. Seol, S.J. Sa, \\ Y.M. Kim \& Y.H. Kim ${ }^{\#}$ \\ National Institute of Animal Science, Rural Development Administration, Cheonan 331-801, Republic of Korea
}

(Received 21 July 2015; Accepted 16 May 2016; First published online 9 September 2016)

\author{
Copyright resides with the authors in terms of the Creative Commons Attribution 2.5 South African Licence. \\ See: http://creativecommons.org/licenses/by/2.5/za \\ Condition of use: The user may copy, distribute, transmit and adapt the work, but must recognise the authors and the South African \\ Journal of Animal Science.
}

\begin{abstract}
This study determined the effect of space allowance on performance, carcass grade and physiological variables of pigs reared in sawdust fermentative pigsties. A total of 699 crossbred (Landrace $\times$ Yorkshire $\times$ Duroc) pigs were housed in sawdust fermentative pigsties and assigned to one of three treatments at different growth stages, namely early grower pigs (EGP), weighing $15-40 \mathrm{~kg}$; late grower pigs (LGP), weighing 40 - $75 \mathrm{~kg}$; and finisher pigs (FP), weighing 75 - $110 \mathrm{~kg}$, with three replicates. The three space allowances for each growth stage were $0.40,0.55$ and $0.70 \mathrm{~m}^{2} /$ head for EGP; $0.55,0.70$ and $0.85 \mathrm{~m}^{2} /$ head for LGP; and $0.85,1.00$ and $1.15 \mathrm{~m}^{2} /$ head for FP. The feed intake in EGP was significantly decreased with increased stocking density. In LGP, the average daily gain (ADG) of pigs reared at high stocking density decreased linearly, whereas the feed conversion ratio increased significantly. The final bodyweight, ADG and feed intake in FP were lower with restricting space allowance. The carcass weight and backfat thickness were significantly higher with increased space allowance. The serum immunoglobulin G levels declined significantly with increased stocking density in all growth stages. The results of this study suggest that the space allowance for maximizing the growth performance and stabilizing immune response of pigs in sawdust fermentative pigsties is $0.55,0.70$, and $1.00 \mathrm{~m}^{2} / \mathrm{pig}$ for the bodyweight ranges of $15-40 \mathrm{~kg}, 40-75 \mathrm{~kg}$, and 75 - $110 \mathrm{~kg}$, respectively.
\end{abstract}

Keywords: Body weight, cortisol, immunoglobulin G, space allowance, stress

\# Corresponding author: yhkims@korea.kr

\section{Introduction}

Piglets weaned from their dams are exposed to various stress-related situations, such as mixing with unfamiliar piglets, struggling for hierarchy, and changes in diets and housing environments (Oh et al., 2010). These factors cause chronic and acute stress and can result in decreased feed intake, lower growth performance and a decline in immunity (Van Heugten et al., 1996; Hyun et al., 2005).

Stocking density is closely related to environmental stresses and directly affects the productivity of pigs. Limited space decreases feed intake and weight gain (Kornegay et al., 1993). Many researchers have reported that the productivity of pigs reared under high-density conditions declines throughout the entire growth phase (Wolter et al., 2000; DeDecker et al., 2005; Kerr et al., 2005). In addition, limited housing density leads to negative effects such as aggressive behaviour, lesions on the skin and a decrease in immunity (Barnett et al., 1992; Weng et al., 1998; Salak-Johnson et al., 2007).

Additionally, consumer groups have criticized the use of excessive stocking density, which reduces the welfare of pigs on commercial farms. Thus, to prevent excessive density on commercial pig farms, a space allowance per pig has been suggested, based on the Livestock Industry Act in South Korea. The space allowance provided is based on the slot floor as follows: $0.3 \mathrm{~m}^{2} / \mathrm{head}$ in the weaning stage (weaning to a bodyweight of $30 \mathrm{~kg}$ ), $0.45 \mathrm{~m}^{2} /$ head in the growing stage (bodyweight of $30-60 \mathrm{~kg}$ ) and $0.8 \mathrm{~m}^{2} / \mathrm{head}$ in the finishing stage (bodyweight greater than $60 \mathrm{~kg}$ ). However, few studies have attempted to determine the optimal space allowance for pigs in sawdust fermentative pigsties because pig farms that use this type of pigsty are rare. In future, the number of housing systems with sawdust pigsties is likely to increase with growing interest in animal welfare (Hötzel et al., 2009). However, there is no current recommended optimal space allowance for pigs housed in sawdust fermentative pigsties in South Korea. Thus, this study was 
performed to investigate the optimal stocking density for maximizing growth performance, carcass grade and immunity of pigs.

\section{Materials and Methods}

The experimental protocols describing the management and care of animals were reviewed and approved by the Animal Care and Use at the National Institute of Animal Science (NIAS). A total of 699 crossbred (Landrace $\times$ Yorkshire $\times$ Duroc) pigs were housed in sawdust fermentative pigsties and assigned to one of three treatments by each growth stage. The experimental animals consisted of an identical ratio of barrows and gilts in a pen. Pigs at three growth stages were evaluated, namely early grower pigs (EGP) 45 days of age ( \pm 2 days) weighing $15-40 \mathrm{~kg}$; late grower pigs (LGP) at 98 days of age ( \pm 3 days) weighing 40 - $75 \mathrm{~kg}$; and finisher pigs (FP) at 140 days of age ( \pm 3 days), weighing $75-110 \mathrm{~kg}$, with three replicates. The three space allowances for each growth stage were 0.40 (T1), 0.55 (T2) and 0.70 (T3) $\mathrm{m}^{2} / \mathrm{head}$ for EGP; 0.55 (T1), 0.70 (T2) and 0.85 (T3) $\mathrm{m}^{2} /$ head for LGP; and 0.85 (T1), 1.00 (T2) and 1.15 (T3) $\mathrm{m}^{2} /$ head for FP. Space available for each pig was altered by varying the number of pigs in the pen. Detailed assignments of the experimental animals and the values of the space allocation coefficient, $\kappa$, corresponding to each space allocation, are presented in Table 1.

Table 1 Area provided to a pig and the space allocation coefficient

\begin{tabular}{llll}
\hline Items & T1 & T2 & T3 \\
\hline Space allowance, $\mathrm{m}^{2} /$ pig & & & \\
$\quad$ EGP & 0.40 & 0.55 & 0.70 \\
LGP & 0.55 & 0.70 & 0.85 \\
FP & 0.85 & 1.00 & 1.15 \\
Number of pigs & & & \\
EGP & 44 & 32 & 25 \\
LGP & 32 & 25 & 21 \\
FP & 21 & 18 & 15 \\
Space allowance coefficient, $\mathrm{K}^{1}$ & & & 0.130 \\
EGP & 0.740 & 0.101 & 0.074 \\
LGP & 0.047 & 0.060 & 0.064 \\
FP & 0.048 & 0.056 & \\
& & & \\
\hline
\end{tabular}

EGP: early grower pig with body weight 15 to $40 \mathrm{~kg}$; LGP: late grower pig with body weights of 40 to $75 \mathrm{~kg}$; FP: finisher pig with body weights of 75 to $110 \mathrm{~kg}$.

${ }^{1}$ The allometric expression of the space coefficient is $\mathrm{K}$, where $\mathrm{k}=$ area in $\mathrm{m}^{2} /$ bodyweight in $\mathrm{kg}^{0.667}$.

The diets were formulated with corn and soybean meal, and met or exceeded the recommendations of the Korean Feeding Standard for Swine (KFSS, 2012) (Table 2). A feeder and water nipple were provided per 10 pigs. All pigs were allowed free access to the feeders and water nipples. The bodyweight and feed consumption of the pigs were determined at the beginning and end of the trial, and ADG and feed conversion ratio (FCR) were calculated.

After the end of the 45-day trial, the finisher pigs were shipped to a commercial slaughter house. The live and carcass weights for the pigs were measured before and after slaughter. The dressing rate was calculated as follows: (carcass weight/live weight) $\times 100$. Backfat thickness (BFT) was measured between the 11th and 12th ribs of the left half carcass after slaughter. In South Korea, carcass grades are scored by a quality panellist, using a score of $+1,1$ or 2 , based on the carcass weight and BFT. The carcasses of the shipped pigs were graded with the Korean carcass grading system for pigs and scored on a scale of 3, 2 and 1 for carcass grades of $+1,1$ and 2 , respectively (Table 3 ). 
Blood samples were collected via the jugular vein on the last day of the experiment and were divided into EDTA-treated tubes and tubes for serum samples. Whole blood in the EDTA tube was used to analyse the complete blood cell count (CBC). Serum samples were obtained by centrifugation for $15 \mathrm{~min}$ at $2000 \times \mathrm{g}$. The supernatant serum was then stored at $-70^{\circ} \mathrm{C}$ until analysis. The $\mathrm{CBC}$ analysis was performed with an automated blood corpuscle analyser (Hemavet HV950FS, Drew Scientific Inc, Miami Lakes, FI, USA), and the serum glucose (GLU), total cholesterol (T-CHO), total protein (T-PRO), triglyceride (TG) and blood urea nitrogen (BUN) concentrations were analysed using an automated clinical analyser (7180, Hitachi, Japan). The concentrations of IgG, TNF- $\alpha$ and cortisol in the serum were determined using ELISA kits (IgG, E101104, BETHYL Laboratories Inc., USA; TNF- $\alpha$, PTA00, R\&D Systems, USA; cortisol, CSB-E06811p, CUSABIO, China) according to the manufacturers' instructions.

Table 2 Nutrient composition of the commercial diet used in this study ${ }^{1}$

\begin{tabular}{lccc}
\hline Items $^{2}$ & Weaning & Grower & Finisher \\
\hline Digestible energy, $\mathrm{kJ} / \mathrm{kg}$ & 14.6 & 14.2 & 14.2 \\
Crude protein, g/kg & 195 & 170 & 160 \\
Lysine, g/kg & 12 & 10 & 9.0 \\
Calcium, g/kg & 6.8 & 5.3 & 4.5 \\
Total phosphorus, g/kg & 5.8 & 4.6 & 4.0 \\
\hline
\end{tabular}

${ }^{1}$ Values are chemical compositions calculated based on the chemical contents of the ingredients.

Table 3 Carcass grading system for pigs in South Korea

\begin{tabular}{lccc}
\hline Grade & Carcass weight, $\mathbf{k g}$ & Backfat thickness, $\mathbf{m m}$ & Score used in this study $^{\mathbf{1}}$ \\
\hline+1 & $83-93$ & $17-25$ & 3 \\
1 & $83-93$ & $15-17$ & 2 \\
1 & $83-93$ & $25-28$ & 2 \\
1 & $80-83$ & $15-28$ & 2 \\
1 & $93-98$ & $15-28$ & 2 \\
2 & & Neither +1 nor 1 grade & 1 \\
\hline
\end{tabular}

${ }^{1}$ The voluntary score was used to express the carcass grade in this study.

All of the growth performance, carcass grade and biochemical and physiological parameter data were analysed statistically in accordance with the GLM (general linear model) procedure, using SPSS version 17.0. The individual pen for the pigs was considered the experimental unit for the statistical analysis in this experiment. The means of all of the measured variables were compared via the polynomial regression method to demonstrate the linear and quadratic effects of the space allowance. Differences were considered significant at $P<0.05$ level, and Duncan's multiple range test (1955) was used to compare treatment means.

\section{Results and Discussion}

The growth performances of the pigs housed in sawdust fermented pigsties are presented in Table 4. At the EGP stage, the average daily feed intake (ADFI) was $14 \%$ and $11 \%$ lower in T1 than in T2 and T3, respectively $(P<0.01)$, although the final bodyweight, ADG and FCR did not differ among treatments $(P$ $>0.05$ ). Each treatment in the LGP had similar ADFIs, whereas the ADG of pigs reared at high density decreased linearly $(P<0.01)$. Accordingly, the FCR was found to be significantly increased in the high density group compared with the low stocking density group $(P<0.01)$. The final bodyweight, ADG $(P<0.05)$ and ADFI $(P<0.01)$ in FP were lower with the small space allowance than the large space allowance. 
Although no significant effect of stocking density on FCR in FP was observed, the FCR was highest in the T1 group $(P>0.1)$. Most researchers have demonstrated that a restricted space allowance decreases daily gain and feed intake in grower-finisher pigs (Edmonds et al., 1998; Brumm et al., 2001; Wolter et al., 2002; Zhang et al., 2013). Brumm \& Gonyou (2001) asserted that a decrease in feed intake is a major response to space restrictions. In the present study, the ADFI in EGP and FP was decreased with increasing stocking density, although the ADFI in LGP was not affected by the restricted space. It is thought that the designed space allowance for LGP in this study might be insufficient to decrease the feed intake compared to the other growth stages. The space allowance coefficient of T1 in LGP was 0.047, which was similar to that in FP. Thus, LGPs, which are smaller than FPs, may experience negligible effects of stocking density under equal space allowance (coefficient 0.047). Street \& Gonyou (2007) reported no significant difference in ADFI between uncrowded pigs $\left(0.78 \mathrm{~m}^{2} / \mathrm{pig}\right)$ and crowded pigs $\left(0.52 \mathrm{~m}^{2} / \mathrm{pig}\right)$ in grower-finisher pigs. Nevertheless, ADG and FCR in LGP decreased linearly with high stocking density $(P<0.01)$. The results of this study are supported by the report of Brumm \& Miller (1996). These results suggest that a high density could retard the growth rate due to lower nutrient availability and chronic stress caused by the social hierarchy and interaction among individuals. Paterson \& Pearce (1991) suggested that an impaired efficiency of feed utilization due to chronic stress is one mechanism by which crowding reduces growth. Serum cortisol, as a marker of stress, increased as the stocking density increased in LGP (Table 7) $(P=0.063)$. The increase in serum cortisol concentration reflects that an experimental animal reared at a high density was placed in a stressful condition in LGP. Although the authors did not investigate nutrient availability in this study, the increase in FCR and serum cortisol level supports the assertions of Brumm \& Miller (1996) and Paterson \& Pearce (1991). In contrast, there was no significant difference in FCR in FP, although ADFI and ADG

Table 4 Effects of stocking density on the growth performance of pigs reared in sawdust fermentative pigsties

\begin{tabular}{lcccccc}
\hline Items & T1 & T2 & T3 & SEM & Linear & Quadratic \\
\hline EGP & & & & & & \\
$\quad$ Initial BW, kg & 12.5 & 12.6 & 12.5 & 0.2 & 0.995 & 0.695 \\
$\quad$ Final BW, kg & 38.4 & 38.3 & 40.3 & 0.8 & 0.308 & 0.521 \\
ADG, g & 447 & 450 & 474 & 10 & 0.282 & 0.638 \\
ADFI, g & $870^{\mathrm{b}}$ & $1005^{\mathrm{a}}$ & $982^{\mathrm{a}}$ & 11 & $<0.01$ & $<0.01$ \\
FCR & 2.41 & 2.49 & 2.29 & 0.10 & 0.654 & 0.518 \\
LGP & & & & & & \\
Initial BW, kg & 39.7 & 40.0 & 39.2 & 0.6 & 0.724 & 0.699 \\
Final BW, kg & 73.0 & 75.0 & 75.6 & 0.7 & 0.153 & 0.658 \\
ADG, g & $659^{\mathrm{b}}$ & $697^{\mathrm{ab}}$ & $724^{\mathrm{a}}$ & 9 & 0.004 & 0.769 \\
ADFI, g & 2020 & 2011 & 2043 & 11 & 0.429 & 0.408 \\
FCR & $3.21^{\mathrm{a}}$ & $2.99^{\mathrm{ab}}$ & $2.90^{\mathrm{b}}$ & 0.05 & 0.008 & 0.525 \\
FP & & & & & & \\
Initial BW, kg & 75.5 & 75.9 & 75.7 & 0.6 & 0.937 & 0.840 \\
Final BW, kg & $106.1^{\mathrm{b}}$ & $109.9^{\mathrm{a}}$ & $108.5^{\mathrm{ab}}$ & 0.6 & 0.097 & 0.038 \\
ADG, g & $716^{\mathrm{b}}$ & $807^{\mathrm{a}}$ & $776^{\mathrm{ab}}$ & 12 & 0.043 & 0.016 \\
ADFI, g & $2624^{\mathrm{b}}$ & $2904^{\mathrm{a}}$ & $2831^{\mathrm{ab}}$ & 20 & $<0.01$ & $<0.01$ \\
FCR & 3.95 & 3.65 & 3.75 & 0.08 & 0.320 & 0.242 \\
& & & & & & \\
\hline
\end{tabular}

T1, T2 and T3: stocking densities as given in Table 1.

EGP: early grower pig with body weight 15 to $40 \mathrm{~kg}$; LGP: late grower pig with body weight 40 to $75 \mathrm{~kg}$; FP: finisher pig with body weights of 75 to $110 \mathrm{~kg}$.

BW: bodyweight; ADG: average daily gain; ADFI: average daily feed intake; FCR: feed conversion ratio.

${ }^{a}, \mathrm{~b}$ Means in the same row with different superscripts differ significantly at $P<0.05$. SEM: standard error of the means. 
Table 5 Effects of stocking density on carcass characteristics of finisher pigs reared in sawdust fermentative pigsties

\begin{tabular}{lcccccc}
\hline Items & T1 & T2 & T3 & SEM & Linear & Quadratic \\
\hline Live weight, $\mathrm{kg}$ & 109.8 & 111.9 & 112.9 & 0.64 & 0.061 & 0.709 \\
Carcass weight, $\mathrm{kg}$ & $83.9^{\mathrm{b}}$ & $84.4^{\mathrm{ab}}$ & $86.8^{\mathrm{a}}$ & 0.54 & 0.037 & 0.381 \\
Dressing rate, \% & 76.3 & 75.4 & 76.9 & 0.16 & 0.177 & 0.156 \\
BFT, mm & $19.2^{\mathrm{b}}$ & $20.5^{\mathrm{ab}}$ & $21.5^{\mathrm{a}}$ & 0.39 & 0.024 & 0.786 \\
Carcass grade, score & 2.22 & 2.29 & 2.04 & 0.08 & 0.384 & 0.346 \\
\end{tabular}

T1, T2 and T3: stocking densities as given in Table 1.

BFT: backfat thickness; SEM: standard error of the means.

${ }^{a, b}$ Means without the same superscript in a row are significantly different $(P<0.05)$.

decreased with the high density. This result is in agreement with other trials (Jensen et al., 1973; Randolph et al., 1981; Ward et al., 1997), which showed no significant differences in FCR in pigs because of limited space allowance.

The results for the serum biochemical components are shown in Table 6. The serum biochemical concentrations were within normal ranges (Klem et al., 2010). The significant effect of stocking density on the biochemical parameters was observed only in the FP group. The authors did not present the results for the biochemical parameters in EGP and LGP because those results were not significant. The glucose concentration was significantly lower $(P<0.05)$ in T1 than in T2 and T3 by 5.8 and $13.6 \mathrm{mg} / \mathrm{dL}$, respectively. The other parameters did not differ among treatment groups. The hematologic results, such as the leukocyte and erythrocyte levels, showed similar levels among all of the treatment groups in all of the growth stages (data not shown).

Table 6 Effects of stocking density on serum biochemical components of pigs reared in sawdust fermentative pigsties

\begin{tabular}{lrrrrrr}
\hline Items & T1 & T2 & T3 & SEM & Linear & Quadratic \\
\hline FP & & & & & & \\
$\quad$ Glucose, $\mathrm{mg} / \mathrm{dL}$ & $67.0^{\mathrm{b}}$ & $72.8^{\mathrm{ab}}$ & $80.6^{\mathrm{a}}$ & 2.0 & 0.016 & 0.005 \\
$\quad$ Total cholesterol, $\mathrm{mg} / \mathrm{dL}$ & 84.1 & 83.6 & 90.6 & 1.9 & 0.243 & 0.164 \\
$\quad$ Total protein, g/dL & 6.9 & 6.9 & 6.7 & 0.1 & 0.159 & 0.097 \\
Triglyceride, IU/L & 44.0 & 53.1 & 45.2 & 2.5 & 0.271 & 0.839 \\
Urea nitrogen, mg/dL & 16.4 & 17.4 & 18.9 & 0.9 & 0.531 & 0.269 \\
$\quad$ Non-esterified fatty acid, $\mu \mathrm{E}$ Eq/L & 52.2 & 48.9 & 51.2 & 2.2 & 0.824 & 0.857 \\
& & & & & & \\
\hline
\end{tabular}

T1, T2 and T3: stocking densities as given in Table 1.

FP, finisher pig with body weights of 75 to $110 \mathrm{~kg}$; SEM: standard error of means.

$\mathrm{a}, \mathrm{b}$ Means without the same superscript in a row are significantly different $(P<0.05)$.

Serum glucose concentration generally decreased with low feed intake. In this study, ADFI in FP decreased at the high density. Thus, it is thought that the decreased serum glucose was caused by the low feed intake in pigs housed at high density. Similarly, Pearce et al. (2013) demonstrated that stress reduces intestinal glucose transport in growing pigs. Low glucose concentration at the limited space allowance might 
be caused by restricted glucose transport in this present study. Additionally, Hemsworth et al. (2002) and Bryer et al. (2011) found that pigs under acute stress had higher glucose levels. Serum glucose is influenced by factors such as stress conditions (intensity, phase, acute and chronic), animals' physiological conditions and nutritional conditions (Pearce et al., 2013). However, these differences have not been clear, and additional research is required to elucidate these results.

The effects of the space allowance on the serum IgG, TNF- $\alpha$ and cortisol levels in the growth stages are shown in Table 7. The serum IgG concentrations for all growth stages were significantly reduced with increased stocking density. The T1 group had the lowest value compared with the others $(P<0.05$ in the EGP and LGP and $P<0.01$ in the FP). Because the differences in T1 and T3 for serum IgG level were 58\%, $53 \%$ and $45 \%$ in EGP, LGP and FP, respectively, the heavier pigs had a wider range of decrease than the lighter pigs. However, there were no effects of stocking density on the serum TNF- $\alpha$ in all the growth stages. The serum cortisol level did not differ in the EGP $(P>0.05)$, although the authors observed an increase in the higher stocking density groups in LGP and FP $(P=0.063$ in LGP; $P=0.103$ in FP $)$.

Table 7 Effects of stocking density on serum IgG, TNF-a and cortisol levels of pigs reared in sawdust fermentative pigsties

\begin{tabular}{|c|c|c|c|c|c|c|}
\hline Items & T1 & T2 & T3 & SEM & Linear & Quadratic \\
\hline \multicolumn{7}{|l|}{ EGP } \\
\hline IgG, $\mathrm{mg} / \mathrm{mL}$ & $54.7^{\mathrm{b}}$ & $78.6^{\mathrm{ab}}$ & $93.0^{\mathrm{a}}$ & 6.3 & 0.010 & 0.684 \\
\hline TNF- $\alpha, p g / m L$ & 100.2 & 111.8 & 118.9 & 7.7 & 0.348 & 0.885 \\
\hline Cortisol, ng/mL & 51.4 & 48.9 & 29.3 & 7.25 & 0.197 & 0.661 \\
\hline \multicolumn{7}{|l|}{ LGP } \\
\hline $\operatorname{lgG}, \mathrm{mg} / \mathrm{mL}$ & $52.8^{b}$ & $66.2^{\mathrm{ab}}$ & $97.8^{\mathrm{a}}$ & 8.6 & 0.033 & 0.604 \\
\hline TNF- $\alpha, p g / m L$ & 63.1 & 74.6 & 73.4 & 5.1 & 0.427 & 0.570 \\
\hline Cortisol, ng/mL & 58.2 & 43.0 & 35.9 & 4.64 & 0.063 & 0.674 \\
\hline \multicolumn{7}{|l|}{$\mathrm{FP}$} \\
\hline $\operatorname{lgG}, \mathrm{mg} / \mathrm{mL}$ & $45.4^{b}$ & $73.5^{\mathrm{ab}}$ & $98.2^{\mathrm{a}}$ & 8.3 & 0.008 & 0.915 \\
\hline TNF- $\alpha, p g / m L$ & 44.9 & 55.3 & 54.2 & 5.0 & 0.461 & 0.608 \\
\hline Cortisol, ng/mL & 77.5 & 67.3 & 38.0 & 9.98 & 0.103 & 0.653 \\
\hline
\end{tabular}

T1, T2 and T3: stocking densities as given in Table 1.

EGP: early grower pig with body weights of 15 to $40 \mathrm{~kg}$; LGP: late grower pig with body weights of 40 to $75 \mathrm{~kg}$; FP: finisher pig with body weights of 75 to $110 \mathrm{~kg}$.

IgG: immunoglobulin G; TNF- $\alpha$ : tumour necrosis factor-alpha; SEM: standard error of means.

${ }^{\mathrm{b}}$ Means without the same superscript in a row are significantly different $(P<0.05)$.

Serum IgG, which plays a major role in defending against antigens in the body, is a typical marker representing the immune system (Deng et al., 2007). Serum IgG is affected by heat stress and social stress. Stress caused by high density impairs the immune function and reduces antibody synthesis (Kelly, 1980). Moreover, activation of the immune system could result in a reduction of feed intake and weight gain (Van Heugten et al., 1996). The observed results, which indicate that high density suppressed the serum IgG content, are sufficient to support this assertion. The decreased growth performance in pigs housed at high density indirectly verifies this assertion. Cortisol, which is commonly used as a marker of stress, is a steroid hormone released from the adrenal cortex. It is well known that cortisol is increased by external stimulation such as heat stress and social stress (Valros et al., 2013). Many studies have reported that the cortisol level rises with increased stocking density (Oh et al., 2010; Hemsworth et al., 2013; Zhang et al., 2013). In the current study, although the serum cortisol level was not affected by high stocking density, throughout each growth stage, pigs housed at high density showed the highest level of serum cortisol, especially in FP, which was approximately double that in T1 compared with T3. 


\section{Conclusion}

In conclusion, the authors observed the effects of space allowance on the growth performance, carcass grade and immunity in pigs housed in sawdust fermentative pigsties. Overall, the results of this study indicate that high density in all growth stages has detrimental effects on growth performance and the immune system. They suggest that the space allowance for maximizing growth performance and stabilizing the immune response of pigs in sawdust fermentative pigsties is $0.55,0.70$ and $1.00 \mathrm{~m}^{2} / \mathrm{pig}$ at a bodyweight of $15-40 \mathrm{~kg}, 40-75 \mathrm{~kg}$ and 75 - $110 \mathrm{~kg}$, respectively. This information can be utilized to optimize the pig production system and enhance the growth performance of pigs reared in sawdust fermentative pigsties.

\section{Acknowledgements}

This work was carried out with the support of the Cooperative Research Programme for Agriculture Science \& Technology Development (Project No. PJ01160301), Rural Development Administration, Republic of Korea. This study was supported by the 2016 Postdoctoral Fellowship Programme of the National Institute of Animal Science, Rural Development Administration, Republic of Korea.

\section{Authors' Contributions}

K.H. Kim and Y.H. Kim conceived and designed the experiments. E.S. Cho, K.S. Kim and J.E. Kim conducted the field trial. K.H. Seol, S.J. Sa and Y.M. Kim collected and analyzed the samples. K.H. Kim wrote the paper. Y.H. Kim discussed and reviewed the paper.

\section{Conflict of Interest Declaration}

The authors declare that they have no conflict of interest.

\section{References}

Barnett, J.L., Hemsworth, P.H., Cronin, G.M., Newman, E.A., McCallum, T.H. \& Chilton, D., 1992. Effects of pen size, partial stalls and method of feeding on welfare-related behavioural and physiological responses of group-housed pigs. Appl. Anim. Behav. Sci. 34, 207-220.

Boddicker, R.L., Seibert, J.T., Johnson, J.S., Pearce, S.C., Selsby, J.T., Gabler, N.K., Lucy, M.C., Safranski, T.J., Rhoads, R.P., Baumgard, L.H. \& Ross, J.W., 2014. Gestational heat stress alters postnatal offspring body composition indices and metabolic parameters in pigs. PLOS ONE 9, e110859.

Brumm, M.C. \& Miller, P.S., 1996. Response of pigs to space allocation and diets varying in nutrient density. J. Anim. Sci. $74,2730-2737$.

Brumm, M.C. \& Gonyou, H.W., 2001. Effects of facility design on behavior and feed and water intake. In: Swine Nutrition. Eds: Lewis, A.J. \& Southern, L.L., CRC Press, Boca Raton, FL. pp. 499-518.

Brumm, M.C., Ellis, M., Johnston, L.J., Rozeboom, D.W. \& Zimmerman, D.R., NCR-89 Committee on Swine Management, 2001. Interaction of swine nursery and grow-finish space allocations on performance. J. Anim. Sci. 79, 1967-1972.

Bryer, P.J., Sutherland, M.A., Davis, B.L., Smith, J.F. \& McGlone, J.J., 2011. The effect of transport and space allowance on the physiology of breeding age gilts. Livest. Sci. 137, 58-65.

DeDecker, J.M., Ellis, M., Wolter, B.F., Corrigan, B.P., Curtis, S.E., Parr, E.N. \& Webel, D.M., 2005. Effects of proportion of pigs removed from a group and subsequent floor space on growth performance of finishing pigs. J. Anim. Sci. $83,449-454$

Deng, Z., Zhang, J., Wu, G., Yin, Y., Ruan, Z., Li, T., Chu, W., Kong, X., Zhang, Y., Fan, Y., Liu, R. \& Huang, R., 2007. Dietary supplementation with polysaccharides from Semen cassiae enhances immunoglobulin production and interleukin gene expression in early-weaned piglets. J. Sci. Food Agric. 87, 1868-1873.

Duncan, D.B., 1955. Multiple range and multiple F tests. Biometrics 11, 1-42.

Edmonds, M.S., Arentson, B.E. \& Mente, G.A., 1998. Effect of protein levels and space allocations on performance of growing-finishing pigs. J. Anim. Sci. 76, 814-821.

Gentry, J.G., McGlone, J.J., Blanton, J.R. \& Miller, M.F., 2002. Alternative housing systems for pigs: Influences on growth, composition, and pork quality. J. Anim. Sci. 80, 1781-1790.

Hemsworth, P.H., Barnett, J.L., Hofmeyr, C., Coleman, G.J., Dowling, S. \& Boyce, J., 2002. The effects of fear of humans and pre-slaughter handling on the meat quality of pigs. Aust. J. Agric. Res. 53, 493-501.

Hemsworth, P.H., Rice, M., Nash, J., Giri, K., Butler, K.L., Tilbrook, A.J. \& Morrison, R.S., 2013. Effects of group size and floor space allowance on grouped sows: aggression, stress, skin injuries, and reproductive performance. J. Anim. Sci. 91, 4953-4964.

Honeyman, M.S. \& Harmon, J.D., 2003. Performance of finishing pigs in hoop structures and confinement during winter and summer. J. Anim. Sci. 81, 1663-1670.

Hötzel, M.J., Lopes, E.J.C., De Oliveira, P.A.V. \& Guidoni, A.L., 2009. Behaviour and performance of pigs finished on deep bedding with wood shavings or rice husks in summer. Anim. Welf. 18, 65-71.

Hyun, Y., Ellis, M., Curtis, S.E. \& Johnson, R.W., 2005. Environmental temperature, space allowance, and regrouping: additive effects of multiple concurrent stressors in growing pigs. J. Swine Health Prod. 13, 131-138.

Jensen, A.H., Baker, D.H., Harmon, B.G. \& Woods, D.M., 1973. Response of growing-finishing male and female swine to floor space allowance on partially and totally slotted floors. J. Anim. Sci. 37, 629-631.

Kelly, K., 1980. Stress and immune function: A bibliographic review. Ann. Res. Vet. 11, 445-478. 
Kerr, C.A., Giles, L.R., Jones, M.R. \& Reverter, A., 2005. Effects of grouping unfamiliar cohorts, high ambient temperature and stocking density on live performance of growing pigs. J. Anim. Sci. 83, 908-915.

KFSS, 2012. Korean Feeding Standard for Swine (2nd ed.). Nutrient Requirements of Swine. National Institute of Animal Science, Wanju-gun, Republic of Korea.

Klem, T.B., Bleken, E., Morberg, H., Thoresen, S.I. \& Framstad, T., 2010. Hematologic and biochemical reference intervals for Norwegian crossbreed grower pigs. Vet. Clin. Pathol. 39, 221-226.

Kornegay, E.T., Lindemann, M.D. \& Ravindran, V., 1993. Effects of dietary lysine levels on performance and immune response of weanling pigs housed at two floor space allowances. J. Anim. Sci. 71, 552-556.

Oh, H.K., Choi, H.B., Ju, W.S., Chung, C.S. \& Kim, Y.Y., 2010. Effects of space allocation on growth performance and immune system in weaning pigs. Livest. Sci. 132, 113-118.

Paterson, A.M. \& Pearce, G.P., 1991. The effect of space restriction during rearing on growth and cortisol levels of male pigs. In: Manipulating Pig Production (3rd ed.), Euroscience, Australasian Pig Science Association, Batterham, Australia. p. 68.

Pearce, S.C., Gabler, N.K., Ross, J.W., Escobar, J., Patience, J.F., Rhoads, R.P. \& Baumgard, L.H., 2013. The effects of heat stress and plane of nutrition on metabolism in growing pigs. J. Anim. Sci. 91, 2108-2118.

Randolph, J.H., Cromwell, G.L., Stahly, T.S. \& Kratzer, D.D., 1981. Effects of group size and space allowance on performance and behavior of swine. J. Anim. Sci. 53, 922-927.

Salak-Johnson, J.L., Niekamp, S.R., Rodriguez-Zas, S.L., Ellis, M. \& Curtis, S.E., 2007. Space allowance for dry, pregnant sows in pens: body condition, skin lesions, and performance. J. Anim. Sci. 85, 1758-1769.

Street, B.R. \& Gonyou, H.W., 2008. Effects of housing finishing pigs in two group sizes and at two floor space allocations on production, health, behavior, and physiological variables. J. Anim. Sci. 86, 982-991.

Valros, A., Munsterhjelm, C., Puolanne, E., Ruusunen, M., Heinonen, M., Peltoniemi, O.A. \& Pösö, A.R., 2013. Physiological indicators of stress and meat and carcass characteristics in tail bitten slaughter pigs. Acta Vet. Scand. 55, 75-82.

Van Heugten, E., Coffey, M.T. \& Spears, J.W., 1996. Effects of immune challenge, dietary energy density, and source of energy on performance and immunity in weanling pigs. J. Anim. Sci. 74, 2431-2440.

Ward, T.L., Southern, L.L. \& Bidner, T.D., 1997. Interactive effects of dietary chromium tripicolinate and crude protein level in growing-finishing pigs provided inadequate and adequate pen space. J. Anim. Sci. 75, 1001-1008.

Weng, R.C., Edwards, S.A. \& English, P.R., 1998. Behaviour, social interactions and lesion scores of group-housed sows in relation to floor space allowance. Appl. Anim. Behav. Sci. 59, 307-316.

Wolter, B.F., Ellis, M., Curtis, S.E., Parr, E.N. \& Webel, D.M., 2000. Group size and floor-space allowance can affect weanling-pig performance. J. Anim. Sci. 78, 2062-2067.

Wolter, B.F., Ellis, M., DeDecker, J.M., Curtis, S.E., Hollis, G.R., Shanks, R.D., Parr, E.N. \& Webel, D.M., 2002. Effects of double stocking and weighing frequency on pig performance in wean-to-finish production systems. J. Anim. Sci. 80, 1442-1450.

Zhang, Z.F., Li, J., Park, J.C. \& Kim, I.H., 2013. Effect of vitamin levels and different stocking densities on performance, nutrient digestibility, and blood characteristics of growing pigs. Asian-Australas. J. Anim. Sci. 26, 241-246. 